\title{
COMMON ERRORS IN THE USE OF THE CALTOX MODEL TO ASSESS THE HUMAN HEALTH RISKS LINKED TO INDUSTRIAL EMISSIONS OF POLLUTANTS
}

\author{
Roseline BONNARD
}

Address: INERIS, Parc Technologique ALATA, BP n 2, 60550 Verneuil-en-Halatte, France

Phone number: 33344556787

Fax number: 33344556899

e-mail: roseline.bonnard@ineris.fr 


\begin{abstract}
The French environmental regulation requires that all the facilities, works and development projects which may affect the environment should be the subject of an impact study to evaluate their consequences, including on human health. For this analysis, the risk assessment approach is used and the population's exposure is estimated with the aid of multimedia models. The CalTOX model is frequently used for this kind of study. Unfortunately, the analysis of these studies shows that the model is often badly understood and badly used. The difficulties encountered by the users, the errors and the problems met in the interpretation of results, which are the most commonly found in the human exposure assessment are listed and their consequences illustrated.

CalTOX has been shown to have a lot of advantages (adaptability, speed in carrying out calculations, transparency), but it ought not to be used as a "black box" as such a use may lead to many errors and a loss of credibility of the studies.
\end{abstract}

Keywords: CalTOX, multimedia-modelling, exposure assessment 


\section{INTRODUCTION}

In France, the law for nature protection (Law no. 76-62) requires industry to conduct an impact study for any facility and development project which may affect the environment. The law on air quality and rational use of energy (Law no. 96-1236) stipulates that one of the main objectives of the impact study is to analyse the effects for human health.

For this analysis, it is recommended to use the risk assessment approach (hazard identification, dose-response evaluation, exposure assessment and risk characterisation). To assess the exposures linked to the implementation of a new industrial facility, the following process is used: characterisation of the source of pollutants, modelling of the pollutant fate in the environment, definition of the exposure scenarios and quantification of the exposure doses.

Currently, the risk assessment studies are conducted by private consultants appointed by the manager of the facility or the people in charge of the development project and these studies are controlled by the local administration. Even if some methodological guidelines (InVS 2000; INERIS 2003) provide advice to choose the models suitable to quantify the exposure for the surrounding population, there is no obligation concerning the way to assess the exposure and no obligation concerning the model or the software to use.

Furthermore, few models applicable on a local scale are able to represent the fate of pollutants between the environmental media and to assess aggregate exposures via multiple exposure pathways. Indeed, most of the models suitable for working on the scale of a site consist of a series of linked models. They cannot address secondary pollutant movements and are seldom able to consider all the potential exposure pathways. As for truly coupled multimedia models, most of them have to be applied on a larger scale: regional, continental or global scales (SETAC 1994; McKone 2003; Fenner 2005). The review, undertaken by EPA, at the beginning of the Total Risk Integrated Methodology (TRIM) project (USEPAa, b) to identify a model able, to apply on variable scales, to consider the conservation of the pollutant mass and secondary pollutant movement presents, CalTOX as "the most promising existing model". Consequently, the French Society of Public Health chose to use CalTOX to assess the risks in the vicinity of incinerators and since this study, many consultants in France and some people in charge to assess the risks linked to incinerators in other countries also use CalTOX.

Unfortunately, the analysis of these studies shows that the model is often badly understood and badly used by risks assessors. CalTOX's developers are not responsible for the mistakes performed in the framework of applications that they could not forecast. Most of the time, the errors are simply linked to a misunderstanding of the parameters' meaning and of the model's concepts by the people in charge of the studies. As CalTOX is extensively used because of its large potentialities, it seems important to give any user the elements to fix these errors, and to recall some rules of good practices when using a model.

After a short description of CalTOX, the difficulties of assigning suitable values to the input parameters, of defining the source term and the most common misuses of CalTOX problems found in the human exposure assessment studies, are listed and their consequences illustrated on the basis of the French experience. 


\section{CALTOX DESCRIPTION}

CalTOX is a multimedia, multiple pathway risk assessment model. It has been developed to assist the California Environmental Protection Agency to estimate the chemical fate and human exposure in the vicinity of hazardous waste sites. The model consists of a set of Excel spreadsheets. An initial version of the model was issued in 1993 and since this date many enhancements have been made. It is composed of two main parts: a multimedia transport and transformation model and a multiple pathway exposure model.

The multimedia transport and transformation model comprises seven environmental compartments in version 2.3 (air, ground-surface soil, root-zone soil, vadose-zone soil, plants, surface water, sediments) and eight in the later version numbered 4.0 (air, groundsurface soil, root-zone soil, vadose-zone soil, cuticle, leaf, surface water, sediments), available on the internet. It is based on a mass-balance system between gains and losses for each compartment. This system is solved as a non-steady-state model for the root-zone soil and vadose-zone soil and as a steady-state model for the other compartments. Therefore, the contaminant inventories in the first two compartments are treated as time-varying state variables, whereas the other compartments are assumed to be in a steady-state with these two soil layers.

The multiple pathway exposure model gives an estimate of the exposure media concentrations and of the exposure doses by inhalation, ingestion and dermal contact.

The model structure is presented in figure 1. For more information, the reader will have to refer to the following documents (McKone 1993, 1997; CalEPA 1993).

\section{PROBLEMS LINKED TO THE ASSIGNMENT OF VALUES TO THE INPUT PARAMETERS}

The CalTOX model is able to take into account many mass-transfer phenomena and exposure pathways, which requires a relatively large number of input parameters. But the assignment of values to the input parameters is often a critical point in the risk assessment studies, due to

> some errors of interpretation concerning the accurate meaning given to the parameters or concerning their actual use in the equations,

> the parameters' variability and/or uncertainty and the model sensitivity to these parameters,

$>$ the lack of scientific data for assigning values to some input parameters.

\section{Examples of misinterpretation of some parameter meanings}

Two examples of misinterpretations are the following:

The first one concerns the surface area of the body. The surface area supposed to be in contact with water or soil is sometimes used as input instead of the total area of the body which actually has to be used (as coefficients equal to 0.8 and 0.3 are present in the equations to assess the actual surface in contact with the tap water when showering or bathing and with soil respectively). 
The second one concerns the flow into the surface water compartment. This parameter called "inflow" must be defined in relation to the surface of the study area. In other words, it has to be defined as the daily volume of water divided by the surface of the study area. Although, the users of the model often assign to this parameter a value corresponding to the daily volume of water going through the section of the water body divided by the surface of this section. Nevertheless, it has to be pointed out that in most of the case studies, the model is not really sensitive to the values of these two parameters.

\section{Examples of the impact of some parameters' variability / uncertainty on the results}

A great deal of effort has been made by the developers to define default values or relationships to calculate default values for all the input parameters. In version 4.0, significant work has been made to develop an extensive database for substances and landscape parameters for several regions of the United States and most of the states (McKone 2003). However, some parameters can be largely variable and/or uncertain and if the model is sensitive to them, large variations of the output can be generated. This is the case with some chemical properties such as the partition coefficients particle/water in soil layers or the bio-transfer coefficient plant/air and, in some applications for environmental parameters such as the "suspended sediment deposit" and the "plant dry mass inventory" (input parameters of the CalTOX version 2.3) as shown below.

The "transfer coefficient plant/air" for 2, 3, 7, 8 TCDD is estimated in the CalTOX version 4.0 as the ratio of the fugacity capacity of the leafy part of the plant on the fugacity capacity of air. By default, it is set equal to $1.010^{4} \mathrm{~m}^{3} / \mathrm{kg}$. In the scientific literature, different values can be found for this parameter ranging from $8.310^{3}$ to $4.1110^{4} \mathrm{~m}^{3} / \mathrm{kg}$ (Mc Crady and Maggard, cited in (CalEPA 1994)). In a test simulation with an air concentration of $2,3,7,8$ TCDD as a pollutant source, the average exposure over the exposure duration is multiplied by 7 , if the geometric mean of these two values is used instead of the default value (with all the other parameters values remaining the same).

In the CalTOX version 2.3, the default values for the environmental parameters are supposed to represent California's landscape properties. The report of the University of CalEPA (CalEPA 1996) indicates that the calculated values for the plant dry mass inventory range from 0 to $16.1 \mathrm{~kg} / \mathrm{m}^{3}$. In fact, the parameter value depends on the soil occupancy. By default, the value used by CalTOX is equal to $2.8 \mathrm{~kg} / \mathrm{m}^{3}$ but for a meadow, for example, the value found in literature is equal to $0.2 \mathrm{~kg} / \mathrm{m}^{2}$ (IPSN 1994). In another test simulation with an atmospheric pollution of 2, 3, 7, 8 TCDD and the CalTOX version 2.3, replacing the first value with the second one leads to a decrease in the average exposure by a factor of 4.5 .

Thus, when the model output is sensitive to some parameters, the users should not be satisfied with the default value of parameters, even for chemical parameters. It is essential that they tailor the model with data relevant for their case study. 


\section{Examples of difficulties due to a lack of scientific data}

To represent the pollutant mass-transfer between two media, CalTOX sometimes uses multiplicative coefficients. In this way, the contribution of the soil pollution to the indoor air contamination is estimated by multiplying the soil gas concentration by the factor "alpha_inair". This calculation method avoids using a complex model based on the diffusion and the advection of pollutant due to the depression in the house. However, defining this parameter appropriately, according to the building and the soil characteristics, is difficult since this parameter is highly variable and little well characterised measurement data is available. The default value in CalTOX is $1 \mathrm{E}-4$, whereas experimental values have been measured between 1 E-2 and 1 E- 4 and a conservative value of 1 E-2 is, for example, recommended in (Umweltbundesamt 1999).

The "rainsplash", the "plant-air partition coefficient" (and the "fraction of irrigation water contaminants transferred to soil" in the CalTOX version 2.3) can raise the same kind of definition problems.

In specific cases, depending on the properties of the substance and the selected pathways of exposure, the model outputs can be sensitive to these parameters. In these cases it is essential that assessors check the relevance of the default values and test the variability and uncertainty of the parameters on the model outputs.

\section{THE WRONG DEFINITION OF THE SOURCE TERM OF POLLUTION}

In many of the impact studies, the source term of pollution is an atmospheric emission from a stack. Therefore, an atmospheric dispersion model is used to calculate the air pollutant concentrations and the pollutant deposit on the surface soil due to the emissions. The calculated air concentration is used to assess the population exposure by inhalation and the deposit of pollutant is entered in a multimedia model as the source term of pollution to quantify the indirect exposures by ingestion and dermal contact.

According to this practice, the parameter called "source term to ground-surface soil" is assigned the value calculated by the atmospheric dispersion model for the pollutant deposit on the surface soil and is used as the source term of pollution in most of the risk assessment studies. But, as CalTOX is a mass-balance model where the feedback loops and secondary pollutant transfers are taken into account, it is important to respect the entrance point of pollution into the system. Defining the source term of pollution as a deposit on the surface soil, whereas it is an emission in the atmosphere, leads to underestimating the pollution impact on the different environmental compartments. Indeed, in these conditions, the air compartment is supposed to be just contaminated by secondary pollutant masstransfers from the other media and the effects of the air dispersion are overestimated.

In order to take into account a source of atmospheric pollution in CalTOX, it is possible either to enter a pollutant flow into the air compartment (Sa expressed in mol/day) or a fixed air concentration by replacing the variable label $\mathrm{Sa}$ with $\mathrm{Ca}$ (in the main CalTOX spreadsheet). 
However, representing the stack emission as a pollutant flow into the air compartment is not relevant for the type of applications defined above, because CalTOX is a zero dimension model. The quantity of emitted pollutant would be diluted into the volume of the study area and the concentrations calculated by the software for the environmental compartment would be inversely proportional to the study area defined by the user of the model. To assess the exposures linked to the atmospheric fallouts from an industrial stack, the assessor should use the pollutant air concentration measured or modelled above the study area.

In table 1 and in figure 2, a case study illustrates the consequences of the wrong definition of the source term on CalTOX's outputs (INERIS, 2003).

The atmospheric dispersion of a 2, 3, 7, 8 tetrachlorodibenzodioxin emission by a power plant has been modelled with a Gaussian model (ARIA Impact model from the company Aria Technologies). Then, CalTOX has been run twice to quantify the population's exposure by ingestion and by dermal contact. First, the source term of pollution has been defined as the maximal deposit on the soil calculated by the atmospheric dispersion model. Then, the source term was set as the maximal air concentration estimated by the same model. With all other input parameters unchanged, the total exposure dose is 23 times smaller in the first simulation $(7.6 \mathrm{E}-11 \mathrm{mg} / \mathrm{kg} / \mathrm{j})$ than in the second one $(1.7 \mathrm{E}-9 \mathrm{mg} / \mathrm{kg} / \mathrm{j})$, and the exposure distribution according to the environmental media and the pathways is very different.

\section{CALTOX'S FEATURES AND SOME UNFITTED USES}

\section{Overestimation of the surface soil concentration and imbalance of the system with version 2.3}

CalTOX estimates the concentration in the air, plants, ground-surface-soil, surface water and sediments compartments as if they were in a steady-state with the root-zone soil and the vadose-zone soil layers.

Yet, in some cases, with version 2.3 of CalTOX, the pollutant residence time in the compartment called "ground-surface soil" is so long that the time needed to hold the steady-state may be longer than the exposure duration.

A test calculation was made with an atmospheric emission of lead equal to $0.1 \mathrm{~mol} / \mathrm{d}$ to illustrate this problem. The chemical properties used are those defined in the database of version 4.0 and the values assigned to all the other parameters are the default values supplied in version 2.3. CalTOX gives a residence time, an inventory and a concentration of lead in the ground soil equal to 129 years, $830 \mathrm{~mol}$ and $10 \mathrm{~g} / \mathrm{kg}$ respectively, whereas the quantity of lead emitted is in fact equal to $547 \mathrm{~mol}$ (number of days of emission per year $\mathrm{x}$ number of year of emission $\mathrm{x}$ daily emission flow $=365 \times 15 \times 0.1$ ). Consequently, the system appears unbalanced and the concentration of lead in the surface soil is greatly overestimated. When the source term of pollution is defined as a continuous input to the air compartment, whatever the substance studied, an imbalance between the input, the output and the remaining quantities in the compartments appears because of the hypothesis of steady-state in the ground-surface soil. 
If the same calculation is made with the later version of CalTOX (all the parameters defined with the default values given in the database, except the root-zone soil adjusted to 1 metre to comply with the requirements of the diffusion model in the soil layers), the residence time, the inventory and the concentration of lead in the surface soil are equal to 16 days, $0.51 \mathrm{~mol}$ and $2.2 \mathrm{mg} / \mathrm{kg}$ respectively. The reduced residence time and the low concentration obtained with this version compared to the previous one is linked to the increase of the mass transfer rate from the surface soil to the root-zone soil by diffusion. Furthermore, the conservation of the pollutant mass in the system is respected.

Since a surrogate flow to air is calculated from the air concentration, defined as pollution source term, to solve the gain and loss equation system, Caltox's later version has to be preferred if the user wants to assess the impact of a continuous emission of pollutant into the air compartment.

\section{Estimate of the exposure linked to background concentrations in the environment}

To assess the risks for populations linked to contaminants, the risk managers ask to take into account the exposure linked to the pollutant background concentration due to the geochemical and/or to the ubiquitous pollution. Therefore, in some studies an exposure calculation is performed by defining the contaminant background concentration in soil as the source term of pollution. This approach is unsuitable, since these concentrations correspond to the steady-state between the continuous gains and losses to and from the soil layers, whereas CalTOX aims to represent how the pollutant mass-inventory in the soil layers will escape with time to the other compartments.

\section{Estimate of the exposure linked to an emission into a river}

Sometimes, CalTOX is used to assess the population exposures linked to a contaminant flow into a river. In this case, CalTOX calculates the contaminant level in the terrestrial media due to the uses of the surface water (irrigation, ingestion by animals) and to the sequence of the following phenomena: pollutant diffusion from surface water to atmosphere, diffusion or deposit from atmosphere to ground-surface soil or to plants. But contrary to some users' belief, CalTOX represents neither the direct mass-transfers from the surface water or from the aquifer to the terrestrial compartments (by overflow or variation of the groundwater level), nor the direct linkage between the aquifer and the surface water compartment.

The misunderstanding of the model's ability led to some misinterpretations of the results and potentially to underestimating the risks in some geographical areas such as the zones liable to flooding. CalTOX has not been developed for such applications.

\section{CONCLUSION}

CalTOX is a multimedia, multiple pathway risk assessment model with many advantages:

$>$ it gives information about the contaminant fate with time in the different environmental media;

$>$ it takes into account many mass transfers and exposure pathways compared to other risk assessment models;

> it gives the user the ability to adapt all the parameters value to the studied case; 
$>$ it gives the user accessibility to all the equations and intermediate results. Therefore it enables the assessor to analyse the suitability of the calculations performed and of the results obtained (i.e. to perform a critical analysis of the model results), which favours the achievement of an essential objective of any risk assessment study: transparency;

$>$ it enables assessing the uncertainty due to parameters easily and rapidly by the Monte-Carlo calculation.

Due to the assets, CalTOX is an interesting first-tier model to assess human exposure in the vicinity of new industrial units. Furthermore, it offers a good balance between adaptability and speed to carry out calculations.

Nevertheless, as any model, whatever the developers' efforts to describe the algorithms, CalTOX can present some difficulties to be used correctly by some users. It has been developed to answer some situations and when used for other cases it may sometimes appear badly fitted. As a general rule, the users must not use the model as a "black box". They have to pay attention to the concepts which the model is based on and to the input parameters' definition to avoid errors and neglecting the results' uncertainty.

\section{ACKNOWLEDGEMENT}

The author gratefully acknowledges Thomas McKone for the paper's review. 


\section{REFERENCES}

ARIA Technologies, ARIA Impact model, Information on the model available at http://www.aria.fr/french/logiciels/niv1/ariaimpact/index.html

CalEPA (California Environmental Protection Agency). 1993, CalTOX, A multimedia total-exposure model for hazardous-waste sites, Part IV : Comments and responses, The Office of Scientific Affairs, Sacramento, CA, USA

CalEPA (California Environmental Protection Agency). 1994, Inter-media transfer for contaminants found at hazardous waste sites, 2,3,7,8-Tetrachlorodibenzo-p-dioxin (TCDD), Final draft report. University of California., Davis, CA, USA

CalEPA (California Environmental Protection Agency). 1996, The distribution of California landscape Variables for CalTOX, Draft report. University of California., Davis, CA, USA

Fenner K., Scheringer M., MacLeod M., Matthies M., McKone T., Stroebe M., Beyer A., Bonnell M., Le Gall A-C., Klasmeier J., Mackay D., Van de Meet D., Pennington D., Scharenberg B., Suzuki N., Wania F., 2005, Comparing estimates of persistence and long-term range transport potential among multimedia models, Environ. Science and . Technology; 2005; 39(7); 1932-1942

INERIS (Institut National de 1'Environnement Industriel et des Risques), 2003, Evaluation des risques sanitaires dans les études d'impact des installations classées, Guide méthodologique, Verneuil-en-Halatte, France

INERIS (Institut National de 1'Environnement Industriel et des Risques), 2003, Analyse critique de l'évaluation des risques pour la santé de la chaufferie urbaine de Montceaules-Mines, DRC-03-47059/ERSA-n¹13-RBn, Verneuil-en-Halatte, France

InVS (Institut de Veille sanitaire), 2000, Guide pour l'analyse du volet sanitaire des études d'impact, Saint-Maurice, France

IPSN (Institut de Protection et de Sûreté Nucléaire), 1994, Contamination des productions agricoles de base suite à une émission atmosphérique accidentelle. Première partie : les modèles de transferts des radionucléides dans la chaîne alimentaire terrestre, SERE, (Service d'Etudes et de Recherches sur les transferts dans l'Environnement), 1994, n94-046, France

McKone T.E.. CalTOX, 1993, A multimedia total exposure model for hazardous-waste sites : UCRL-CR-111456. Lawrence Livermore National Laboratory, Livermore, CA, USA

McKone T.E., Hall D., Kastenberg W.E, 1997, CalTOX version 2.3, Description of modifications and revisions. prepared for the Department of Toxic Substances Control, Berkeley, CA, USA

McKone T.E., Bennett, 2002, Chemical-specific representation of air-soil exchange and soil penetration in regional multimedia models, Report LBNL-46693, Berkeley, CA, USA

McKone T.E., MacLeod M., 2003, Tracking multiple pathways of human exposure to persistent multimedia pollutants: regional, continental, and global scale models, Annual review of environment and resources, Vol. 28 : 463-492

Ministère de l'Environnement, Law n $76-629$ du 10 Juillet 1976 relative à la protection de la nature. Journal Officiel de la République Française du 13 Juillet 1976, Paris, France 
Ministère de 1'Environnement, Law n96-1236 du 30 Décembre 1996 sur l'air et l'utilisation rationnelle de l'énergie, Journal Officiel de la République Française du ler janvier 1997, Paris, France

SETAC (Society of Environmental Toxicology and Chemistry), 1994, Multi-media fate models : a vital tool for predicting the fate of chemicals, SETAC Press, Pensacola, FL, USA

SFSP (Société Française de Santé Publique), 1999, L'incinération des déchets et la santé publique : bilan des connaissances récentes et évaluation du risque. Collection Santé \& société $n^{\circ} 7$, Vandoeuvre-les-Nancy, France

USEPA (U.S. Environmental Protection Agency), 2002a, Total Risk Integrated Methodology, TRIM.Fate, Technical Support Document, Volume I. EPA-453/R-02011a. Office of Air Quality Planning and Standards, NC, USA

USEPA (U.S. Environmental Protection Agency), 2002b, Total Risk Integrated Methodology, TRIM.Fate, Technical Support Document, Volume 2. EPA-453/R-02011b. Office of Air Quality Planning and Standards, NC, USA

Umweltbundesamt, 1999, Bundes-Bodenschutz- und Altlastenverordnung (BBodSchV), 17 July 1999. Germany. Text available at http://www.umweltbundesamt.de 
Figure 1: CalTOX scheme

\section{Contaminant source term}

Multimedia transport and transformation model

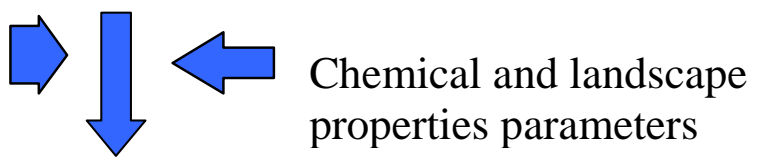

Contaminant concentrations in the environmental media

Multiple pathways exposure model

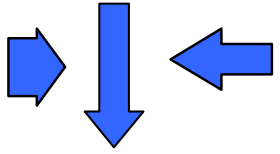

Chemical properties and human exposure parameters

Contaminant concentrations in the exposure media

Multiple pathways exposure model
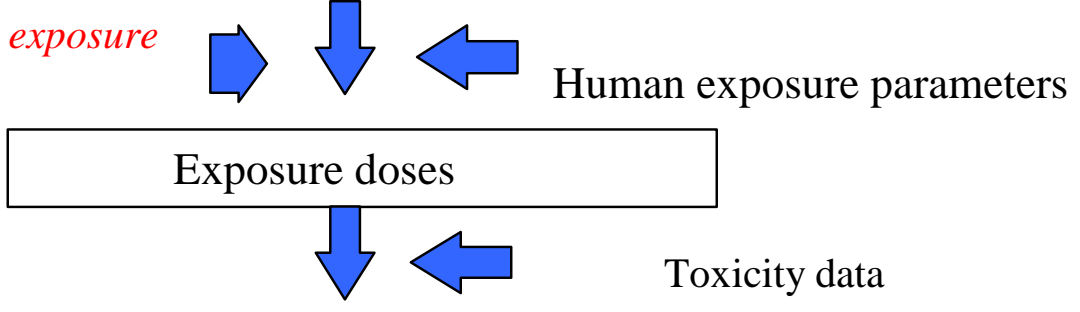

Risk and hazard ratio 
Table 1: Main assumptions of the case study

\begin{tabular}{|l|l|}
\hline Source term of pollution & $\begin{array}{l}\text { Atmospheric emissions of 2, 3, 7, } 8 \mathrm{TCDD} \\
\text { Maximal air concentration modelled : } 1.9 \mathrm{E}-8 \mu \mathrm{g} / \mathrm{m}^{3} \\
\text { Maximal ground deposit modelled: } 7.3 \mathrm{E}-11 \mu \mathrm{g} / \mathrm{m}^{2} / \mathrm{s}\end{array}$ \\
\hline $\begin{array}{l}\text { Environmental and exposure } \\
\text { parameters }\end{array}$ & $\begin{array}{l}\text { Deposit velocity of air particles: } 0.4 \mathrm{~cm} / \mathrm{s} \\
\text { Emission and exposure are concomitant } \\
\text { The same environment and exposure parameters are used in } \\
\text { both simulations }\end{array}$ \\
\hline Exposure pathways & $\begin{array}{l}\text { Soil ingestion } \\
\text { Water ingestion } \\
\text { Vegetables and fruit ingestion } \\
\text { Meat ingestion } \\
\text { Milk ingestion } \\
\text { Egg ingestion } \\
\text { Mother milk ingestion } \\
\text { Dermal contact with soil } \\
\text { Dermal contact with water }\end{array}$ \\
\hline
\end{tabular}


Figure 2: Exposure distribution according to the compartments and the pathways a: simulation made with a deposit on the surface soil as contaminant source term

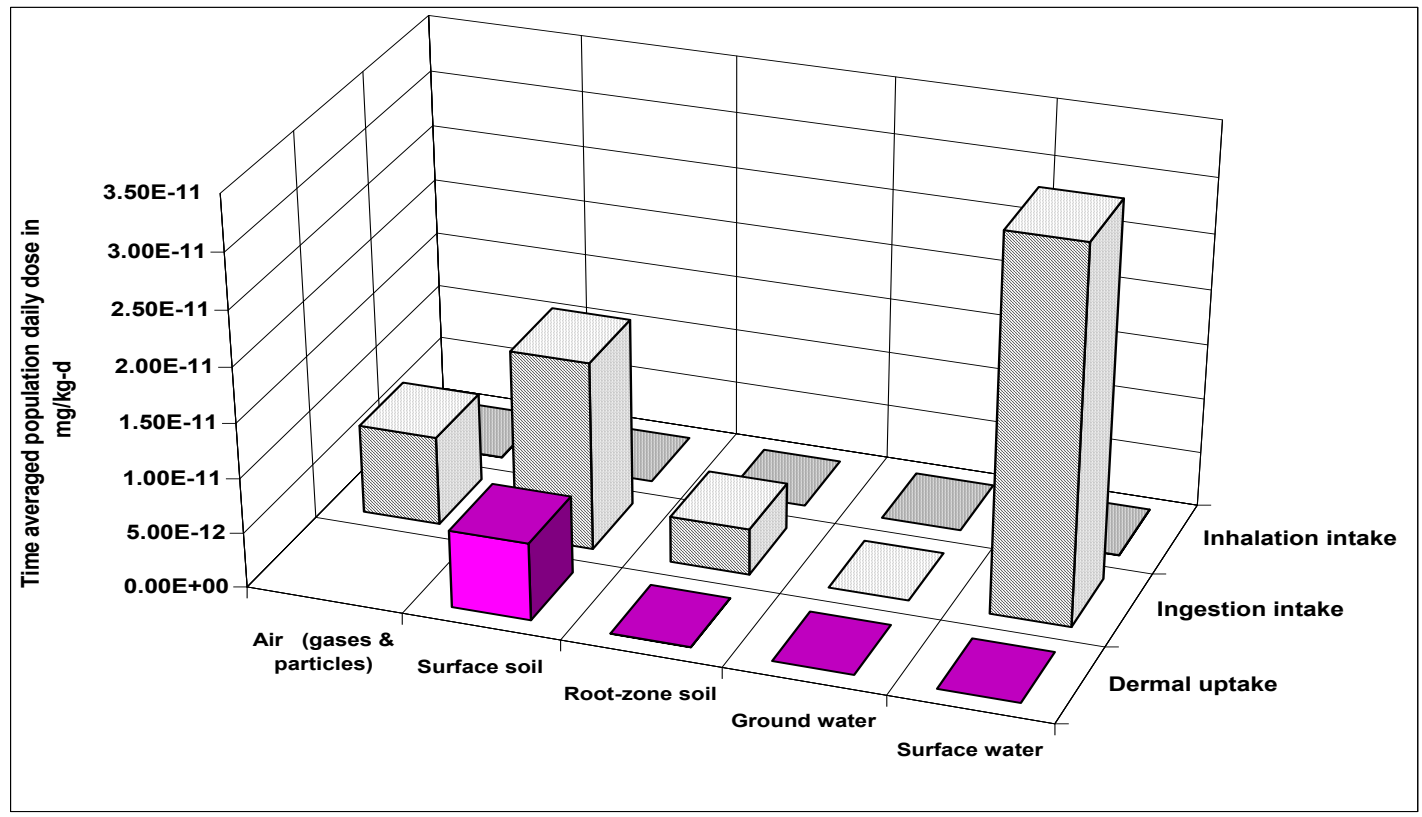




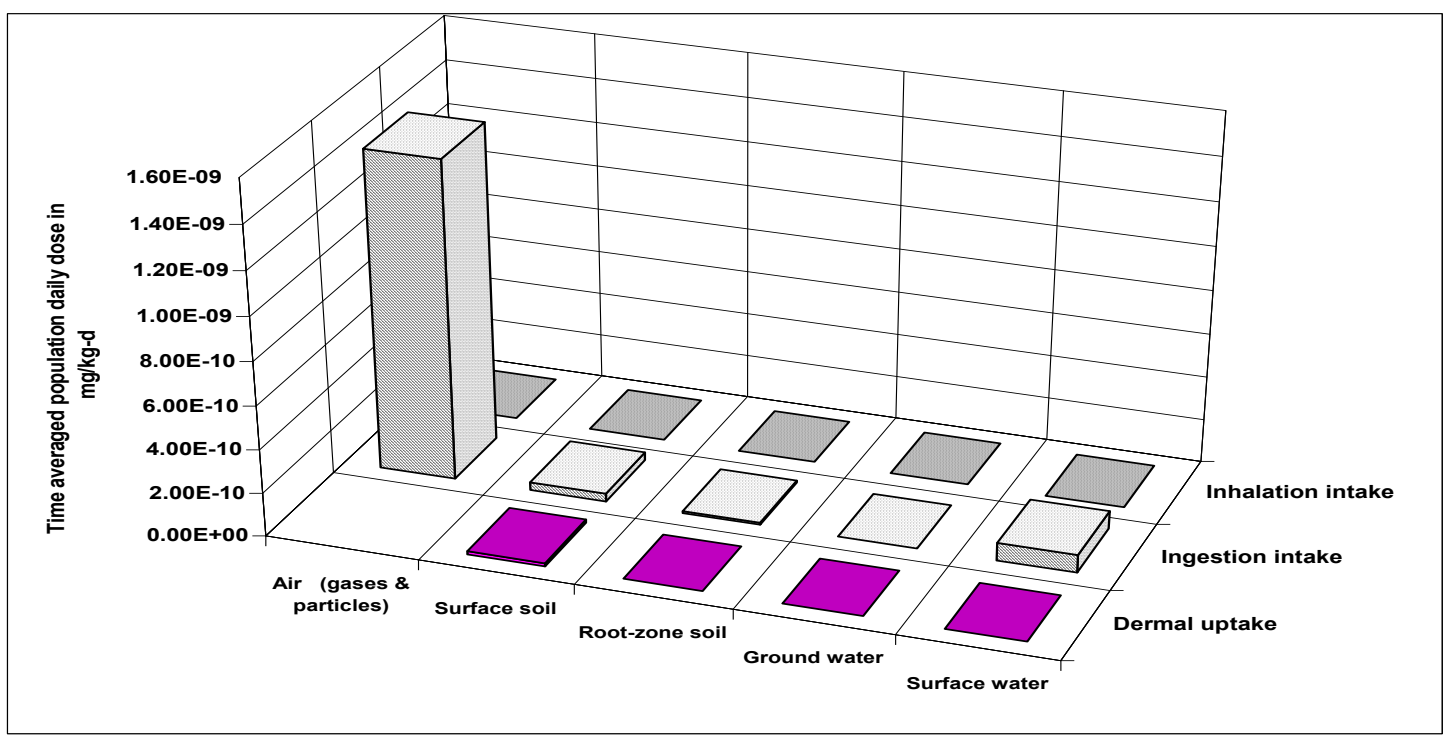

b: simulation made with the air concentration as contaminant source term 